\title{
SPACE QUALIFIED S-BAND TRANSMITTER FOR GPS DATA MODULATION FOR THE BRAZILIAN TECHNOLOGICAL SATELLITE
}

Ivan Tosetto, Rodolfo Araujo, Carlos Gonçalves and José A. Rodrigues. INPE - Instituto Nacional de Pesquisas Espaciais - São José dos Campos, SP, Brasil

\begin{abstract}
This paper describes a S-Band Transmitter (TX) for the Technological Satellite (SATEC) using commercial SMD components emphasizing the designs concepts and tests results. The S-Band TX was designed to transmit GPS (Global Positioning System) data on BPSK format, modulated at 2.2044 GHz. The Transmitter was fully tested at INPE facilities within spatial requirements for flight qualifying. The tests results presented give the good performance of the equipment.
\end{abstract}

Index Terms - Technological satellite, s-band transmitter, space qualified, reliability.

\section{INTRODUCTION}

The SATEC (Technological Satellite) developed by INPE, is based on the micro satellite vanguard technology [1] and on the experience resulted from the development of the Brazilian Space Program.

SATEC is a low orbit satellite with altitude near $750 \mathrm{~km}$ and inclination about 15 degrees with respect to Earth's equatorial plane.

The satellite should be launched on July 2003 by the Brazilian Satellite Launcher Vehicle-VLS.

The most important characteristics of this project are the optimization of all features to make available volume, mass and power in order to maximize the payload requirements with reduced costs.

A S-Band Transmitter at $2.2044 \mathrm{GHz}$ was developed to modulate GPS data on BPSK format an transmit to the ground station.

In order to reduce time and costs, this equipment was designed to use commercial SMD components. To qualify these components they were baked out to eliminate and avoid humidity, also some additional tests including Burn-In, Vibration, Thermal-Vacuum and Thermal Cycling were performed to demonstrate that these SMD components were ready to use. A Solithane C 113- Adhesive was used to seal up the plastic encapsulated integrated circuits

\section{TRANSMITTER DESCRIPTION}

The S-Band Transmitter block diagram is shown in Figure 2. The equipment is designed to receive data from the onboard GPS receiver at $5 \mathrm{kbps}$, to modulate, amplify and transmit the signal from satellite to ground station. TX is assembled in three boxes as defined:

$$
\text { a. Micro-controller / Synthesizer }
$$
b. DC/DC Converter
c. RF Box (Modulation + Amplification)

In Figure 1 we have the picture of the RF box flight model assembled.

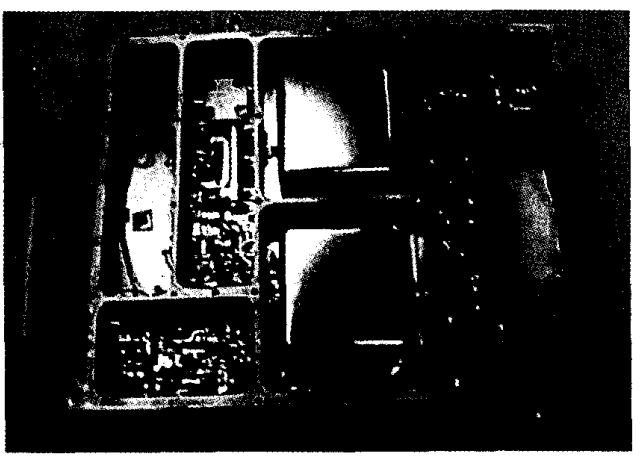

Figure 1-RF box flight model picture

The DC power is supplied by DC/DC converts in order to obtain good performance and to reduce noise interference from the power line on TX circuits.

To improve reliability cold redundancy configuration was used as shown in Figure 2, which in case of RF power failure on TX1 (main TX) automatically changes the power supply from TX1 to TX2. Both RF output power are connected to a hybrid. The reliability analysis will be shown in Item $\mathrm{V}$.

The DC/DC Converter obtains from the main bus line $(+28 \mathrm{~V})$ the correct voltages $(+15 \mathrm{~V}$ and $+5 \mathrm{~V})$ to $\mathrm{TX} 1$ and $\mathrm{TX} 2$ circuitry, offers protection from voltage overshooting and conducted noise interference. It also provides the circuit for TX's switching.

The Synthesizer is a phase-looked oscillator (PLO) integrated circuit - PLL400-2200 from Vari-L - with a TCXO as input reference frequency $(18.37 \mathrm{MHz})$ programmed via serial data from Micro-controller module. Multiplying internally by 120 , providing $2.2044 \mathrm{GHz}$ at output with high stability and low phase noise due to TCXO characteristics. 


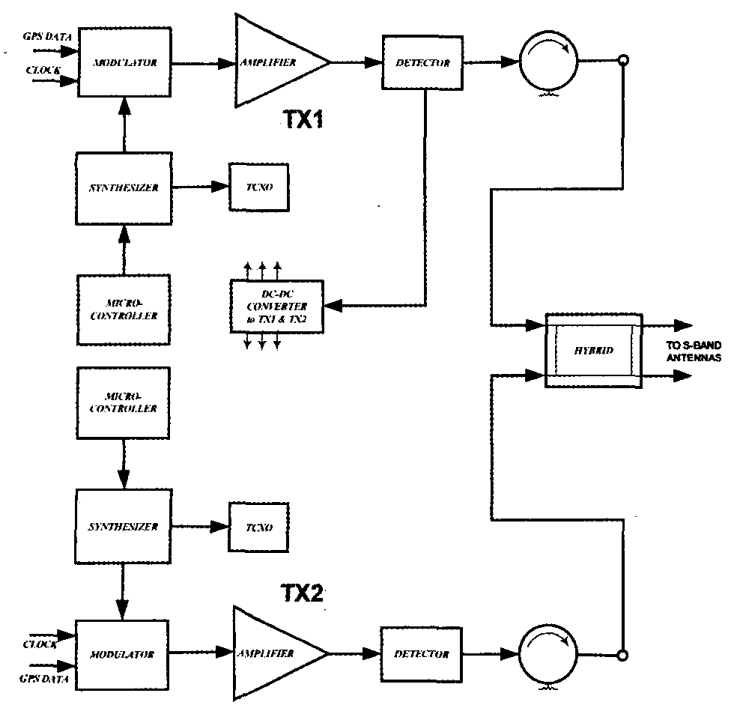

Fig. 2 - S-Band Transmitter Block Diagram

The Micro-controller is used to program the synthesizer through two serial words (R- reference divider word and $\mathrm{N}$ feedback divider word). To guarantee the correct output frequency, at each two hours the synthesizer is automatically reprogrammed. Also in case of loss of lock, the microcontroller send the programming words.

On the modulation side, the RF2422 modulator used is a monolithic quadrature modulator integrated circuit from RF Micro Devices capable of direct modulation for high frequency with an output RF amplifier which drives 50 ohms from $800 \mathrm{MHz}$ to $2500 \mathrm{MHz}$.

In our application it was used as a bi-phase modulator by connecting the $\mathrm{I}$ and $\mathrm{Q}$ inputs together.

According to internal IC's circuits, the output signal is always suppressed (with or without modulating signal). In order to verify others TX functions an interface circuit was added to obtain the nominal carrier. In the presence of modulating signal, BPSK output has always suppressed carrier.

To obtain the desired RF output power two high efficiency monolithic integrated amplifiers were used in cascade: a preamplifier and a medium power module, RF2310 and RF2189 respectively, giving $+23 \mathrm{dBm}$ in output for the required link budget. The link budget analysis will be shown in Item VI

\section{QUALIFICATION / ACCEPTANCE TESTS}

To improve performance and to qualify the commercials components used on TX, basically IC monolithic circuits (amplifiers, modulator, synthesizer, etc.), some additional precautions were taken before assembling, in the following sequence:

- Beak out at $+55^{\circ} \mathrm{C}$ for 72 hours;

- Seal out the top plastic cover with Solithane C 113Adhesive.

Besides these actions the environmental tests done on TX, as described below, will qualify the components giving guarantee that they will operate adequately during the mission.

The Transmitter was submitted to extensive testing in a simulated space environment performing the following qualification and acceptance tests sequence:

- Visual Inspection / Dimensional Inspection / Mass Properties;

- Functional Test

- Burn - In

- Functional Test

- Thermal Test / Functional Test

- Thermal Cycling / Functional Test

- Thermal Vacuum / Functional Test

- Vibration

- Final Functional Test

1. Functional Test

According to electrical performance requirements for this equipment the Functional Test [2] is composed by DC Power Consumption, Output Frequency, In-Rush Current, Chain 1 Off / Chain 2 On, Switching Time, RF Output Power, Output Return Loss, Turn-On Time, Thermal Noise Floor, Spurious \& Harmonics, Modulation Parameters.

The specifications [3] for all these parameters are showed on test result table.

\section{Burn-In}

This test was performed just to anticipate possible early life failures on commercials components. Each chain of TX was kept turned on for 24 hours at $+55^{\circ} \mathrm{C}$ and after this period a Functional Test was run to verify any degradation.

\section{Thermal Test}

The TX flight model itself was submitted to temperatures $10^{\circ} \mathrm{C}$ over the nominal temperature range at qualification level to guarantee some margin on its nominal operation. Two important TX parameters were verified in this test: RF minimum power and BPSK carrier suppression / unbalance. This test was performed for the range of $-20^{\circ} \mathrm{C}$ to $+55^{\circ} \mathrm{C}$ in steps of $10^{\circ} \mathrm{C}$.

\section{Thermal Cycling}

Each chain of the equipment was submitted to the thermal cycling profile show in figure 3 . A reduced functional test was accomplished during $\mathrm{T} 1, \mathrm{~T} 2, \mathrm{~T} 3, \mathrm{~T} 4, \mathrm{~T} 5$ and $\mathrm{T} 6$ temperatures. 


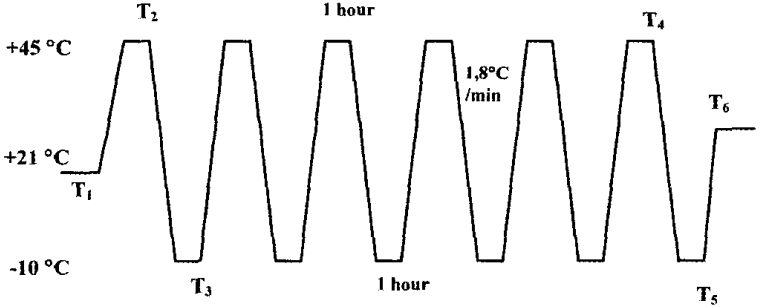

Figure 3 - Thermal cycling profile

5. Thermal Vacuum

In this test the equipment was subjected to the specified temperature and pressure profiles according to TX / SATEC Thermal Vacuum Test Specification. The Functional Test was performed in hot $\left(+45^{\circ} \mathrm{C}\right)$ and cold $\left(-10^{\circ} \mathrm{C}\right)$ temperature limits as seen in Figure 4.

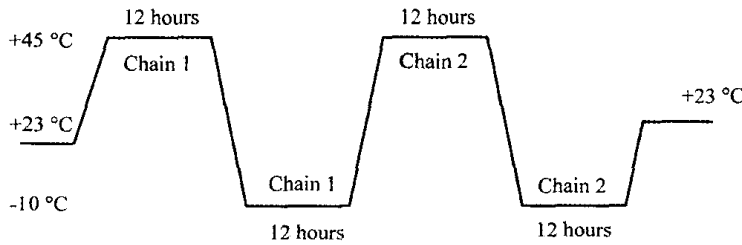

Figure 4 - Thermal vacuum profile

6. Vibration

To simulate the same conditions during launch, the equipment was submitted to sine and random vibration with the purpose of verification of mechanical evaluation. The Vibration Test was performed according to TX / SATEC Vibration Test Specification. After this test a final functional test was performed.

\section{RESULTS}

This section presents some representative results of the Transmitter's Chain 1 for all tests done.

The Figure 5 presents the measured output modulated signal for a Bi-Phase coded modulating input signal at Initial Functional Test

The Figure 6 and 7 show the measured output modulated signal in $-10^{\circ} \mathrm{C}$ for a square wave and for a Bi-Phase coded modulating input signals, respectively, performed during thermal vacuum test. We can observe in Figure 6 that the carrier suppression is $-29.5 \mathrm{dBc}$.

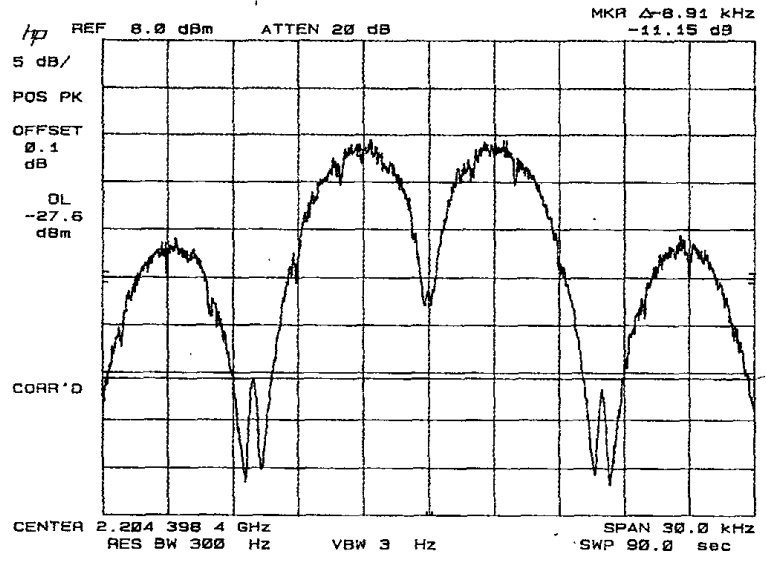

Figure 5

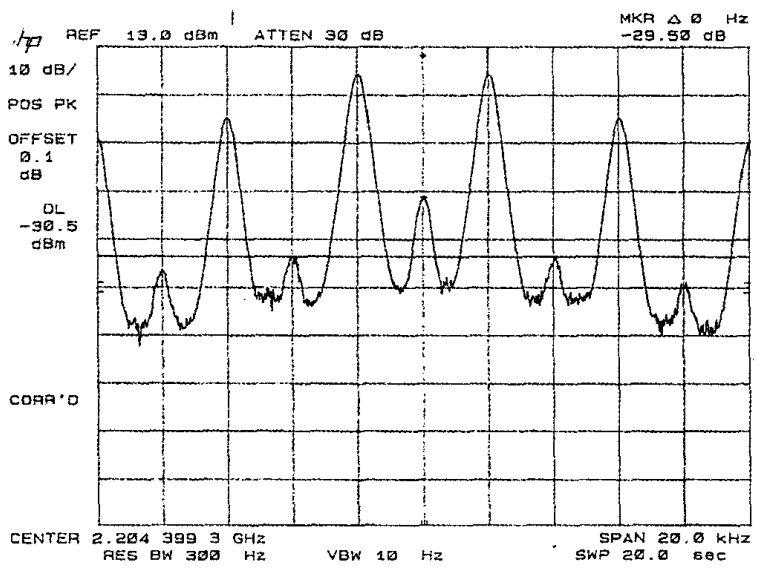

Figure 6

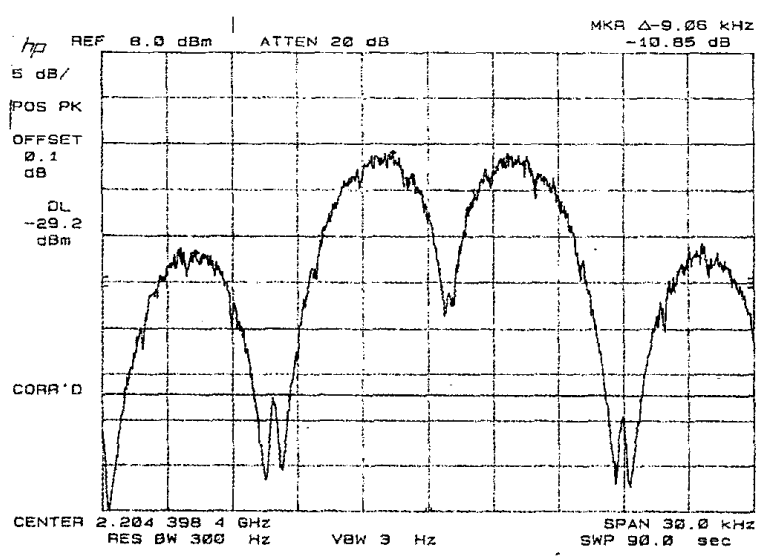

Figure 7 
The Figure 8 presents the measured output modulated signal for a Bi-Phase coded modulating input signal at Final Functional Test.

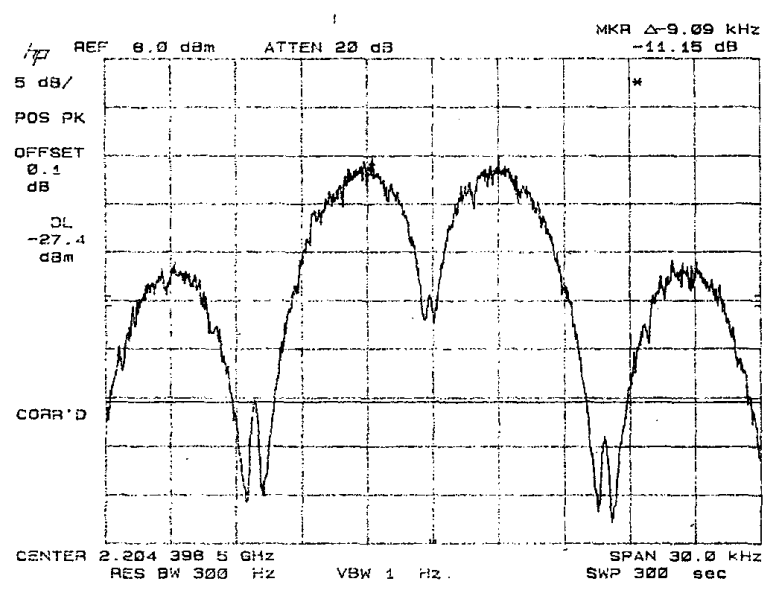

Figure 8

The Figure 9 presents the measured output demodulated signal (video) for a Bi-Phase coded modulating input signal at Final Functional Test.

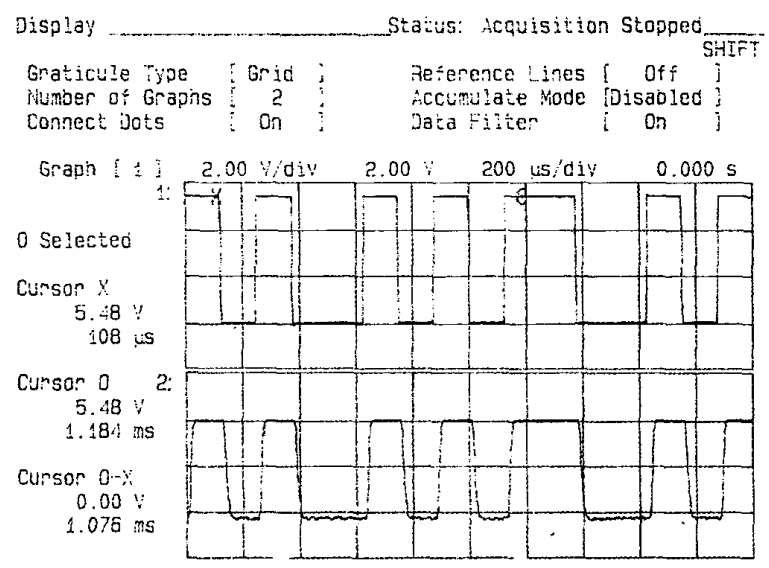

Figure 9

\section{IV.1. TABLE OF TEST RESULTS}

\begin{tabular}{|c|c|c|}
\hline TEST & SPECIFIED & MEASURED \\
\hline Power Consumption (W) & 4.5 & 4.24 \\
\hline Output Frequency (MHz) & $2204.4 \pm 0.004$ & 2204.398665 \\
\hline In-Rush Current (mA) & 1000 & 239 \\
\hline $\begin{array}{c}\text { Chain 2 On / Chain 1 Off } \\
\text { Time (ms) }\end{array}$ & $<500$ & 380 \\
\hline RF Output Power (dBm) & $21(-0 /+2 \mathrm{~dB})$ & 22.25 \\
\hline Output Return Loss (dB) & $>15$ & 12.9 \\
\hline
\end{tabular}

\begin{tabular}{|c|c|c|}
\hline TEST & SPECIFIED & MEASURED \\
\hline Turn -On Time (s) & $<1$ & 0.129 \\
\hline $\begin{array}{c}\text { Thermal Noise Floor } \\
(\mathrm{dBm})\end{array}$ & $<-110$ & -138.5 \\
\hline $\begin{array}{c}\text { Spurious / Harmonics } \\
(\mathrm{dBc})\end{array}$ & $<-50$ & $<-65$ \\
\hline $\begin{array}{c}\text { Modulated Carrier } \\
\text { Rejection (dBc) }\end{array}$ & $>25$ & 29.6 \\
\hline Incidental AM (\%) & 20 & 13.5 \\
\hline
\end{tabular}

\section{RELIABILITY CALCULATION}

An important aspect of satellite reliability is the fact that satellites must operate in space without benefit of repairs or maintenance. Under these circumstances, it is imperative that all parts, components and subsystems must be exposed to extensive tests in a simulated space environment.

In order to increase the reliability, the TX was designed with redundancy to assure successful performance.

The equipment reliability is defined as the probability that the equipment works according its specification in a known time interval.

This analysis was performed according the following considerations:
a. Parts counting method (MIL-HDBK-217F);
b. Constant Failure Rate for the electrical parts;
c. Mission Lifetime: 6 months (4380 Hours);
d. Quality level of the parts $(\pi \mathrm{q})$

The reliability function for each module is:

$$
R(t)=e^{-\lambda t}
$$

where $\lambda$ is the failure rate of each module and $t$ is the lifetime

The expression for the total TX reliability was evaluated using cold redundancy [4]:

$$
\begin{aligned}
& R_{T x}=\left(e^{-\lambda_{1} \times t}\right) \times\left[1-\left(1-e^{-\left(\lambda_{2}+\lambda_{3}\right) \times t}\right)^{2}\right] \times \\
& \left(e^{-\lambda_{4} \times t}\right) \times\left[1-\left(1-e^{-\lambda_{5} \times t}\right)^{2}\right] \times\left(e^{-\lambda_{6} \times t}\right)^{4}
\end{aligned}
$$

So we have:

$$
\begin{aligned}
& R_{T x}=0,99905 \\
& \lambda_{\mathrm{TX}}=217 \text { FITS }
\end{aligned}
$$

where $\lambda_{T X}$ is the total TX Failure Rate in FITS $\times 10^{-9} \mathrm{~h}$

Since the Transmitter is always powered on, the dormant failure rate was not considered. 


\section{LINK BUDGET}

This section explains the calculation of the SATEC link budget. Downlink at $2.2044 \mathrm{GHz}$ :

1 - Calculated carrier to noise density ratio $\left(\mathrm{C} / \mathrm{N}_{0}\right)$

Satellite EIRP:

$-18,0 \mathrm{dBW}$

Losses:

Clear sky downlink loss (2675 km, $5^{\circ}$ elev.): $167,9 \mathrm{~dB}$

Polarization + Pointing loss:

Total Losses:

$\overline{168,9 \mathrm{~dB}}$

Earth Station G/T:

(Boltzman Constant) ${ }^{-1}$

$21,0 \mathrm{~dB} / \mathrm{K}$

228,6

Calculated $\mathrm{C} / \mathrm{N}_{0}$

$62.7 \mathrm{dBHz}$

2 - Required carrier to noise density ratio $\left(\mathrm{C} / \mathrm{N}_{0}\right)$

Specified $\mathrm{Eb} / \mathrm{N}_{0}$ :

$10,5 \mathrm{~dB}$

$2,5 \mathrm{~dB}$

Implementation Losses:

$37,0 \mathrm{dBHz}$

Data Rate $(5 \mathrm{~kb} / \mathrm{s}, \mathrm{BPSK})$ :

$50,0 \mathrm{dBHz}$

Required $\mathbf{C} / \mathbf{N}_{0}$

$12,7 \mathrm{~dB}$

Link Margin:

Maximum power flux density on Earth:-150,5 dBW/4 kHz

\section{CONCLUSION}

This paper describes the development of a S-Band Transmitter based on the micro satellite technology to be used on the Technological Satellite.

The goal of this project were the use of commercial components previously qualified for the mission in order to reduce costs, project time and qualifying this equipment to be used in futures satellites.

The success of the environmental tests results confirmed that the previously qualification on the components has been done successfully. The final functional test results complied with the electrical specifications.

\section{REFERENCES}

[1] C. Gonçalves and L. Cividanes. "Communication subsystem strategy for the brazilian small scientific satellite", $4^{\text {th }}$ International Symposium for Small Satellites Systems and Services, Antibes - France, 1998.

[2] R. Araujo, I. Tosetto, J. Rae, J.A. Rodrigues and C. Gonçalves. "Procedimento de Testes do Transmissor SATEC", doc. SATEC-TSP-001, INPE - São José dos Campos, SP, 2002

[3] J. A. Rodrigues. "Especificação do Transmissor Banda-S SATEC", doc DEA-TL-059/02, INPE - São José dos Campos, SP, 2002.

[4] J. Wiley, "Handbook on satellite communications", Third Edition, J Wiley \& Sons, Inc., USA, 2002. 